Pacific Journal of Mathematics

ON THE NUMBER OF INTEGERS IN THE SUM OF TWO SETS 


\title{
ON THE NUMBER OF INTEGERS IN THE SUM OF TWO SETS OF POSITIVE INTEGERS
}

\author{
HEN RY B. MAN N
}

1. Introduction. Let $A, B, \cdots$ be sets of nonnegative integers. We define

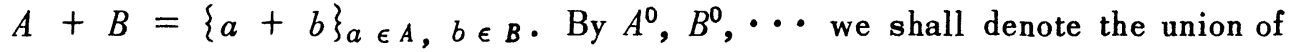
$A, B, \cdots$ and the number 0 , by $A(n)$ the number of positive $a$ 's that do not exceed $n$. We further put

$$
\text { g.l.b. } \frac{A(n)}{n}=\alpha \text {, }
$$

$$
\text { g.l.b. } \frac{A(n)}{n+1}=\alpha^{*} \text {, }
$$$$
\lim \inf \frac{A(n)}{n}=\bar{a} \text {. }
$$

If $1,2, \cdots, k-1 \in A, k \notin A$, we further put

$$
\underset{n \geq k}{\text { g.1.b. }} \frac{A(n)}{n+1}=\alpha_{1} \text {. }
$$

The real number $\alpha$ is called the density of $A, \alpha_{1}$ the modified density, and $\bar{\alpha}$ the asymptotic density of $A$. Densities of $A, B, C, \cdots$ will be denoted by the corresponding Greek letters $\alpha, \beta, \gamma, \cdots$.

Besicovitch [1] introduced $\alpha^{*}$, and Erdös [2] $\alpha_{1}$.

The author [3] proved: If $C=A^{0}+B$ for $B \ni 1$ and $A^{0}+B^{0}$ otherwise, then for all $n \notin C$ we have

$$
C(n) \geq \alpha^{*} n+B(n) \text {. }
$$

It was also shown [3] that in (5), $\alpha^{*}$ cannot be replaced by $\alpha$. 
It is the purpose of the present note to improve (5) to the relation

$$
C(n) \geq a_{1} n+B(n) \text {. }
$$

The proof of (6) requires only a modification of the proof of (5), but will be given in full to make the present note self-sufficient.

The inequality (6) immediately yields

$$
\bar{\gamma} \geq a_{1}+\bar{\beta}
$$

if $C$ has infinitely many gaps.

Now (7) is sometimes better and sometimes not as good as Erdös' [2] inequality

$$
\bar{\gamma} \geq \bar{\alpha}+\bar{\beta} / 2
$$

for the case $\alpha>\beta, B \ni 1, C=A^{0}+B^{0}$. (To establish (8) it is really sufficient to assume that there is at least one $b^{0}$ such that $b^{0}+1 \in B$.) However (7) holds also for $C=A^{0}+B$ if $B \ni 1$, and for $C=A^{0}+B^{0}$ without any restriction on $B$.

2. Proof. We shall now give a proof of (6) for the case $C=A^{0}+B, B \ni 1$, and then shall indicate the changes which have to be made if nothing is assumed about $B$ but if $C=A^{0}+B^{0}$. By $a, b, c, \cdots$ we shall denote unspecified integers in $A, B, C, \cdots$.

Let $n_{1}<n_{2}<\cdots$ be all the gaps in $C$. Put $n_{r}=n, n-n_{i}=d_{i}$ for $i<r$. If there is one $e \in B$ such that

$$
a+e+d_{i}=n_{j},
$$

form all numbers $e+d_{t}$ for which

$$
a+e+d_{t}=n_{s}, \quad t<r, \quad s<r .
$$

Let $T$ be the set of indices occurring in (10). Put $B^{*}=\left\{e+d_{s}\right\}_{s \in T}$. It is not difficult to prove the following propositions.

Proposition 1. The intersection $B \cap B^{*}$ is empty.

Proposition 2. The integer $n$ is not of the form $a+e+d_{s}$ for any $s$.

Since (10) also implies

$$
a+e+d_{s}=n_{t},
$$


it follows that $B^{*}$ contains as many numbers as there are gaps in $C$ which precede $n$ and which are not gaps in $A+B \cup B^{*}$. Hence we have the following result.

Proposition 3. If $B \cup B^{*}=B_{1}, A+B_{1}=C_{1}$, then

$$
C_{1}(n)-C(n)=B_{1}(n)-B(n) .
$$

Thus we have proved the following lemma.

LEMMA. If there is at least one equation of the form $a+b+d_{i}=n_{j}$, then there exists a $B_{1} \supset B$ such that $C_{1}=A+B_{1}$ does not contain $n$, and such that

$$
C_{1}(n)-C(n)=B_{1}(n)-B(n)>0 .
$$

Now let $C=A^{0}+B, B \ni 1$. Clearly, $n_{1}>1$. The numbers smaller than $n_{1}$ are either in $B$, or of the form $n_{1}-a$, or of neither of these two sorts. Also $n_{1} \notin B$, since $C \supset B$. Hence we have

$$
C\left(n_{1}\right)=n_{1}-1 \geq A\left(n_{1}-1\right)+B\left(n_{1}\right) .
$$

Since $B \ni 1$, we must have $n_{1}-1 \notin A,\left(n_{1}-1\right) \geq k$. Thus, we obtain

$$
C\left(n_{1}\right) \geq \alpha_{1} n_{1}+B\left(n_{1}\right) \text {. }
$$

We proceed by induction and assume (6) proved, when $n$ is the $j$ th gap, $j<r$. We distinguish two cases.

Case 1: $d_{r-1}<n_{1}$. Then

$$
C \exists n_{1}-d_{r-1}=a+b \text {. }
$$

We now apply the lemma. Let $n$ be the $j$ th gap in $C_{1}$. Then $j<r$, and we have, by induction,

$$
C_{1}(n) \geq \alpha_{1} n+B_{1}(n),
$$

and, by the lemma,

$$
C_{1}(n)-C(n)=B_{1}(n)-B(n) .
$$

Subtracting (16) from (15), we obtain (6).

Case 2: $d_{r-1} \geq n_{1}$. Now

$$
n-n_{r-1}-1 \geq n_{1}-1 \notin A .
$$


Hence we have

$$
A\left(n-n_{r-1}-1\right) \geq \alpha_{1}\left(n-n_{r-1}\right) .
$$

The numbers between $n_{r-1}$ and $n$ are either of the form $n-a$, or in $B$, or of neither of these two sorts. But $n \notin B$; hence,

$$
\begin{aligned}
n-n_{r-1}-1 \geq A\left(n-n_{r-1}-1\right) & +B(n)-B\left(n_{r-1}\right) \\
& \geq \alpha_{1}\left(n-n_{r-1}\right)+B(n)-B\left(n_{r-1}\right) .
\end{aligned}
$$

By induction we have

$$
C\left(n_{r-1}\right)=n_{r-1}-(r-1) \geq \alpha_{1} n_{r-1}+B\left(n_{r-1}\right) .
$$

Adding (17) and (18), we obtain (6).

From the proof it is evident that we may obtain the even stronger inequality

$$
C(n) \geq \alpha_{1} n+B(n)+\min _{n_{i} \leq n}\left[\frac{A\left(n_{i}-1\right)}{n_{i}}-\alpha_{1}\right] n_{i} .
$$

To establish (6) for $C=A^{0}+B^{0}$ without the restriction $B \ni 1$, we first remark that in (13) the term $A\left(n_{1}-1\right)$ can be replaced by $A\left(n_{1}\right)$. The cases to be distinguished are $d_{r-1} \leq n_{1}$ and $d_{r-1}>n_{1}$. The proof of Case 1 is then word by word the same when we replace $B$ by $B^{0}$ and $B_{1}$ by $B_{1}^{0}$. In Case 2 we have

$$
n-n_{r-1}-1 \geq n_{1} \geq k \text {, }
$$

so that $A\left(n-n_{r-1}-1\right) \geq \alpha_{1}\left(n-n_{r-1}\right)$; the remainder of the argument remains unchanged. For $C=A^{0}+B^{0}$, we can obtain the even stronger inequality

$$
C(n) \geq \alpha_{1} n+B(n)+\min _{n_{i} \leq n}\left[\frac{A\left(n_{i}\right)}{n_{i}}-\alpha_{1}\right] n_{i},
$$

which again implies the even stronger result

$$
\begin{aligned}
C(n) \geq \max \left\{\alpha_{1} n+B(n)+\right. & {\left[\frac{A\left(n_{1}\right)}{n_{1}}-\alpha_{1}\right] n_{1}, } \\
& A(n)+\beta_{1} n+\min _{n_{i} \leq n}\left[\frac{B\left(n_{i}\right)}{n_{i}}-\beta_{1}\right] n_{i} .
\end{aligned}
$$


To establish (7), it is sufficient to show that for any set $S$ we have

$$
\frac{S(m)}{m}>\frac{S(n)}{n}
$$

if $m>n, n \notin S, S(m)-S(n)=m-n$. However, this can easily be verified. Thus if $S$ has infinitely many gaps, then

$$
\bar{\sigma}=\lim \inf \frac{S(m)}{m}=\lim _{n \notin S} \inf \frac{S(n)}{n} .
$$

It thus appears that in (7) we may replace $\bar{\beta}$ by

$$
\lim _{n \notin C} \inf \frac{B(n)}{n} \geq \bar{\beta}
$$

If $C=A^{0}+B^{0}$, we may of course write

$$
\bar{\gamma} \geq \max \left(\alpha_{1}+\bar{\beta}, \quad \bar{\alpha}+\beta_{1}\right)
$$

\section{REFERENCES}

1. A. S. Besicovitch, On the density of the sum of two sequences of integers, J. London Math. Soc. 10 (1935), 246-248.

2. P. Erdös, On the asymptotic density of the sum of two sequences, Ann. of Math. 43 (1942), 65-68.

3. H. B. Mann, A proof of the fundamental theorem on the density of sums of sets of positive integers, Ann. of Math. 43 (1942), 523-527.

Ohio State University 



\title{
PACIFIC JOURNAL OF MATHEMATICS
}

\section{EDITORS}

\author{
Herbert BuSEMANN \\ R. M. RoBINSON \\ University of Southern California \\ University of California \\ Los Angeles 7, California \\ Berkeley 4, California \\ E. F. BEC KENBACH, Managing Editor \\ University of California \\ Los Angeles 24, California
}

\section{ASSOCIATE EDITORS}
R. P. DILWORTH
P. R. HALMOS
BØRGE JESSEN
J. J. STOKER
HERBERT FEDERER
HEINZ HOPF
PAUL LÉVY
MARSHALL HALL
R. D. JAMES
GEORGE PÓLYA
E. G. STRAUS
KÖSAKU YOSIDA

\section{SPONSORS}

UNIVERSITY OF BRITISH COLUMBIA

CALIFORNIA INSTITUTE OF TECHNOLOGY

UNIVERSITY OF CALIFORNIA, BERKELEY

UNIVERSITY OF CALIFORNIA, DAVIS

UNIVERSITY OF CALIFORNIA, LOS ANGELES

UNIVERSITY OF CALIFORNIA, SANTA BARBARA

OREGON STATE COLLEGE

UNIVERSITY OF OREGON
UNIVERSITY OF SOUTHERN CALIFORNIA

STANFORD UNIVERSITY

WASHINGTON STATE COLLEGE

UNIVERSITY OF WASHINGTON

AMERICAN MATHEMATICAL SOCIETY

NATIONAL BUREAU OF STANDARDS, INSTITUTE FOR NUMERIGAL ANALYSIS

Mathematical papers intended for publication in the Pacific Journal of Mathematics should be typewritten (double spaced), and the author should keep a complete copy. Manuscripts may be sent to any of the editors. All other communications to the editors should be addressed to the managing editor, E. F. Beckenbach, at the address given above.

Authors are entitled to receive 100 free reprints of their published papers and may obtain additional copies at cost.

The Pacific Journal of Mathematics is published quarterly, in March, June, September, and December. The price per volume (4 numbers) is $\$ 8.00$; single issues, $\$ 2.50$. Spécial price to individual faculty members of supporting institutions and to members of the American Mathematical Society: $\$ 4.00$ per volume; single issues, $\$ 1.25$.

Subscriptions, orders for back numbers, and changes of address should be sent to the publishers, University of California Press, Berkeley 4, California.

UNIVERSITY OF CALIFORNIA PRESS - BERKELEY AND LOS ANGELES 


\section{Pacific Journal of Mathematics}

\section{Vol. 1, No. $2 \quad$ December, 1951}

Tom M. (Mike) Apostol, On the Lerch zeta function ................. 161

Ross A. Beaumont and Herbert S. Zuckerman, A characterization of the subgroups of the additive rationals ....................... 169

Richard Bellman and Theodore Edward Harris, Recurrence times for the Ehrenfest model................................... 179

Stephen P.L. Diliberto and Ernst Gabor Straus, On the approximation of a function of several variables by the sum of functions of fewer

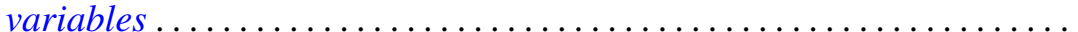

Isidore Isaac Hirschman, Jr. and D. V. Widder, Convolution transforms with complex kernels ................................ 211

Irving Kaplansky, A theorem on rings of operators .............. 227

W. Karush, An iterative method for finding characteristic vectors of a symmetric matrix............................... 233

Henry B. Mann, On the number of integers in the sum of two sets of positive integers ......................................... 249

William H. Mills, A theorem on the representation theory of Jordan

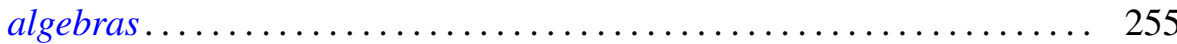

Tibor Radó, An approach to singular homology theory.............. 265

Otto Szász, On some trigonometric transforms ................... 291

James G. Wendel, On isometric isomorphism of group algebras ......... 305

George Milton Wing, On the $L^{p}$ theory of Hankel transforms ... 